\title{
EXPERIMENTAL AND THEORETICAL STUDY OF FORCED CONVECTION AROUND A CYLINDER EMBEDDED IN POROUS MEDIA
}

\author{
Abeer Aamer \\ abeeraamer537@gmail.com, \\ suhad Abd-hameed \\ Sah_Jumaily66@yahoo.com \\ University of Technology/Mechanical Engineering Department
}

\begin{abstract}
An experimental and theoretical study of air forced convection heat transfer at Reynolds number (1091.5 to 1560) around a circular cylinder placed in an iron test section $(0.2 \times 0.2 \times 0.4$ $\mathrm{m}^{3}$ ) filled with saturated porous material glass balls of $5 \mathrm{~mm}$ in diameter. A copper circular cylinder heater of diameter $0.015 \mathrm{~m}$ and length $0.2 \mathrm{~m}$ is heated electrically; it is located in different positions in $\mathrm{X}$ and $\mathrm{Y}$ direction within the test section. The forced convection heat transfer is simulated using the ANSYS program (Fluent). The results showed that the surface temperature distribution of the cylinder has the same trends for the different locations within the test section. The average Nusselt number increases with Reynolds number and heat flux. Also, the results show that the use of porous material improves heat transfer by $67.4 \%$. The maximum percentage deviation between the experimental and theoretical results is $1.622 \%$. Moreover, experimental correlations were introduced and comparison was performed between the present results with the previous studies and it gives a good agreement.
\end{abstract}

KEYWORDS: Porous media, Forced convection, Heater model

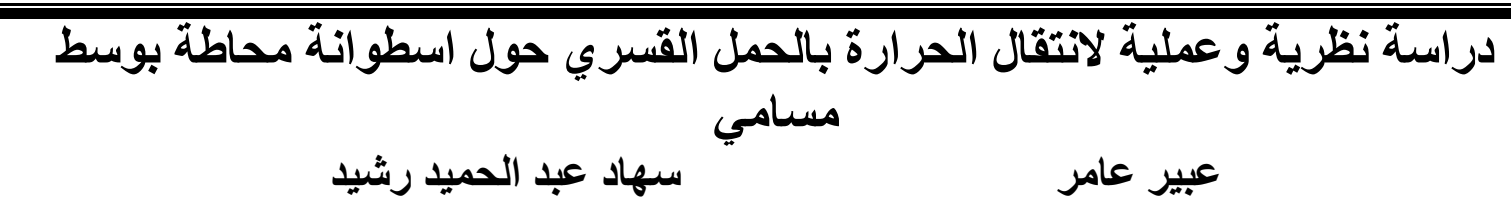

الخلاصة

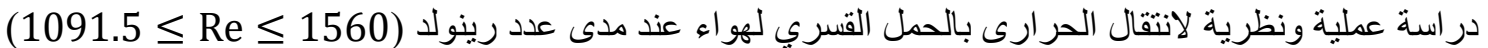

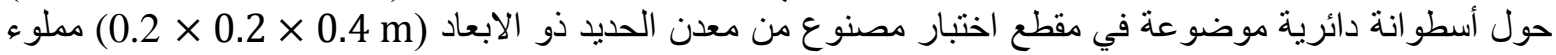

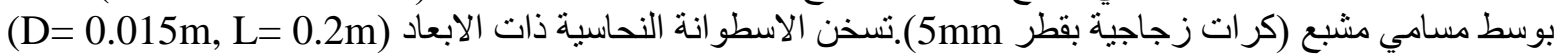

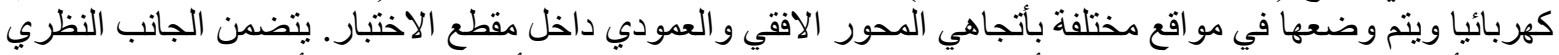

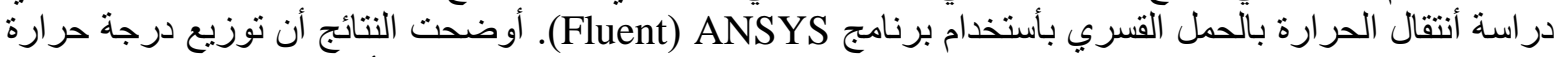

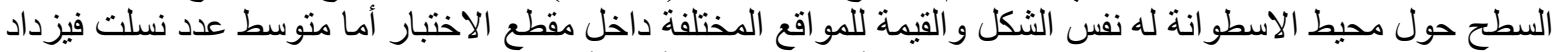

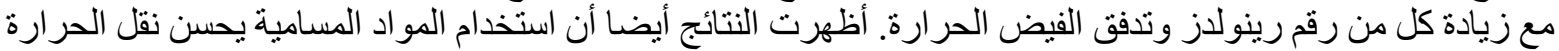

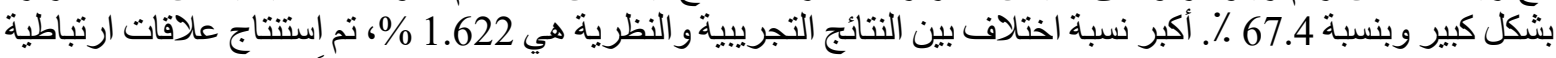
لكل حالة تجريبية وتم إجر اء مقارنة بين نتائج البحث الحالي و الدراسات السابقة ، وقية وقد اعطى اتفاقًا جيدًا.

$$
\text { الكلمات المفتاحية: الوسط المسامي, الحمل القسري, نموذج مسخن }
$$

Received : 23-10-2019

Accepted :25-12-2019 


\begin{tabular}{|c|c|c|}
\hline $\begin{array}{c}\text { NOMENCL } \\
\text { Symbol }\end{array}$ & URE & Units \\
\hline A & Area of test section & $\mathrm{m}^{2}$ \\
\hline $\mathrm{A}_{\mathrm{s}}$ & The heating element area & $\mathrm{m}^{2}$ \\
\hline $\mathrm{c}_{\mathrm{p}}$ & Air specific heat at constant pressure & $\mathrm{J} / \mathrm{kg} \cdot \mathrm{K}$ \\
\hline $\mathrm{D}$ & The circle cylinder diameter & $\mathrm{m}$ \\
\hline $\mathrm{h}$ & The average heat transfer coefficient & $\mathrm{W} / \mathrm{m}^{2} \cdot{ }^{\circ} \mathrm{C}$ \\
\hline$h_{\ominus}$ & The local heat transfer coefficient & $\mathrm{W} / \mathrm{m}^{2} \cdot{ }^{\circ} \mathrm{C}$ \\
\hline$\varepsilon$ & Porosity & - \\
\hline I & Electrical Current & A \\
\hline $\mathrm{k}_{\mathrm{m}}$ & Effective thermal conductivity of porous media & $\mathrm{W} / \mathrm{m} \cdot \mathrm{K}$ \\
\hline $\mathrm{k}_{\mathrm{f}}$ & thermal conductivity of air & $\mathrm{W} / \mathrm{m} \cdot \mathrm{K}$ \\
\hline $\mathrm{k}_{\mathrm{s}}$ & Thermal conductivity of spheres (beads) & $\mathrm{W} / \mathrm{m} \cdot \mathrm{K}$ \\
\hline$Q_{t}$ & electrical power & W \\
\hline$m_{a n r}$ & Mass flow rate of air & $\mathrm{kg} / \mathrm{s}$ \\
\hline $\mathrm{q}$ & Heat flux & $\mathrm{W} / \mathrm{m}^{2}$ \\
\hline $\mathrm{Nu}_{\Theta}$ & local Nusselt number & - \\
\hline $\mathrm{Nu}$ & average Nusselt number & - \\
\hline $\operatorname{Re}$ & Reynold number & - \\
\hline $\operatorname{Pr}$ & Prandtl number & - \\
\hline $\mathrm{T}_{\text {in }}$ & Temperature inlet airflow of test section & ${ }^{\circ} \mathrm{C}$ \\
\hline $\mathrm{T}_{\text {out }}$ & Temperature outlet airflow of test section & ${ }^{\circ} \mathrm{C}$ \\
\hline $\mathrm{T}_{\mathrm{w}}$ & surface temperature of the heater model & ${ }^{\circ} \mathrm{C}$ \\
\hline $\mathrm{T}_{\mathrm{w} \Theta}$ & The local surface temperature of heater model & ${ }^{\circ} \mathrm{C}$ \\
\hline $\mathrm{U}$ & Average Velocity in the test section & $\mathrm{m} / \mathrm{s}$ \\
\hline $\mathrm{V}$ & Electrical voltage & $\mathrm{V}$ \\
\hline$\propto$ & permeability & $\mathrm{m}^{2}$ \\
\hline $\begin{array}{c}\mathrm{p} 1, \ldots, \mathrm{p} 7 \\
x \\
\mathrm{X}\end{array}$ & $\begin{array}{l}\text { position number of the heater within the test section } \\
\text { the distance between one location and another }(5 \mathrm{~cm}) \\
\text { the length of test section }(40 \mathrm{~cm})\end{array}$ & $\begin{array}{c}- \\
\mathrm{cm}\end{array}$ \\
\hline
\end{tabular}

\section{INTRODUCTION}

The field of research in the past three decades, especially after the energy crisis that arose when Arab oil was cut off from the world markets in the October 1973 war (Alsammarraie2007), is to stimulate work in two directions, the first trend is to find a new alternatives to oil energy, such as renewable energies (solar, wind and hydropower), The second trend is to rationalize energy consumption by improving the performance efficiency of heat exchange systems and thermal cycles by searching for catalysts that can be used in a useful way to increase the amount of heat transfer from such systems, such as porous media that have a great heat transfer capacity by Absorption and cooling using three heat transfer methods (conduction, convection and radiation). The porous medium is used in many fields and applications. It has been used in industry, geology and nuclear industries. They also play an important role in the field of heat transfer and in energy conservation, such as granular or porous insulators, and high-capacity electrical winding structures (Bejan 1984). The porous medium is also used in nuclear reactors, drying, absorbing solar energy storage, building materials and insulating materials ( $\mathrm{Al}$ - Omar ). Nasr et.al (1994) studied experimentally air forced convection around a cylinder of $(12.7 \mathrm{~mm}$ diameter) embedded in the spherical particles bed with a porosity of 0.37 and diameters of the packed bed are $3,6,13 \mathrm{~mm}$. The effect of diameter of the particles and the thermal conductivity in the range of $200 \mathrm{~W} / \mathrm{m} \mathrm{K}$ for aluminum to $0.23 \mathrm{~W} / \mathrm{m} \mathrm{K}$ for nylon) are examined. With a packed bed, the heat transfer 
coefficient is enhanced seven times. The heat transfer coefficient for small particles and higher thermal conductivity is higher. Layeghi et.al (2006) studied numerically with the finite volume element the convective heat transfer around a cylinder immersed in a porous medium at Peclet numbers less than 40.. Darcy model has utilized to analysis heat transfer and fluid flow. The power-law scheme was utilized. The results showed that Nusselt number is affected by the porosity, where it was increased as the porosity decreased, also the pressure drop in the porous media is affected by the permeability, where it was increased as the permeability decreases. Al-Sumaily el.al(2012), studied numerically Time-dependent forced convection from a circular cylinder immersed in the horizontal spherical packed bed under a local nonequilibrium thermal condition using the spectral-element method. The non-Darcian effects were taken into account. The solid-to-fluid thermal conductivity ratio is $k_{r}(0.01,1000)$ and Biot number $\mathrm{Bi}$ is $(0.01,100)$. The Reynolds number $R e_{D}$ is $(1,250)$. The results of the porous media enhanced considerably the heat transfer and suppressed significantly the wakes behind the heater and increase in Bi decreases Nuf. Also, for $\mathrm{kr}>10 \mathrm{Nu}_{\mathrm{f}}$ increase with increase kr. A.l Eleiwi (2012), studied experimentally and Theoretically forced convection heat transfer around a cylinder in cross-flow embedded in a saturated glass sphere of $4,8,12 \mathrm{~mm}$. The practical part involves creating a device consists of (blower, air duct, test section, heating model), the heater model is made of copper with a $13 \mathrm{~mm}$ diameter. the theoretical part has been resolved the momentum and energy equations with a Peclet number $(1<\mathrm{Pe}<10)$. Both the experimental and theoretical results showed that the average heat transfer increase as the Peclet number increase. Al-Sumaily el.al (2014) studied numerically forced-convection heat transfer of four circular cylinders (in-line, a staggered arrangement) embedded in metallic or non-metallic porous materials. The space between cylinder centers ( $\mathrm{SP} \in[1.5,3.0]$ ), Reynolds numbers $\operatorname{Re}_{D} \in[1,250]$ and, solid-to-fluid thermal conductivity ratios $K_{r}=1.725,57.5,248$. The results reveal that the thermal performance of in-line arrangement is lower than that for staggered one. And both local Nusselt number, $N u_{f \varphi}$ and average Nusselt number, $N u_{f}$ are dependent greatly on the cylinder arrangement, $R e_{D}$, SP. the trend of the differences of $N u_{f}$ With SP is not considerably changed by $K_{r}$. Mirlatifi and Ghazal(2014) studied experimentally the effect of using Spherical glass porous media of $6 \mathrm{~mm}$ diameter on the steady-state air forced-convection heat transfer from a circular cylinder heater. Mean Nusselt number was calculated into two cases, with \& without porous media and the results shows that using the porous medium improves the heat transfer rate. Abood(2016) studied experimentally the effect of the shape of heater element on heat transfer from a circular, triangular and, square cylinder embedded in the spherical glass of $3 \mathrm{~mm}$ of steady-state forced convection. Average Nusselt Number was found in porous media and the results were explained in dimensionless form. The investigation shows a maximum increase of heat transfer from the circular heater in porous media from the triangle and square heater.

The aim of the present work is to carry out experimental and theoretical study for forced convection heat transfer of circular cylinder embedded in a porous media in the different locations within the test section with constant heat flux and study the effects of changing heat flux, air flow rate and the position of the heater model within the test section with and without porous media on heat transfer.

\section{THEORETICAL WORK}

In this section, the thermal performance and electrical characteristics of cylinder cooling by porous media (forced convection) are evaluated. This section describes the physical model by using the SOLID WORK (2018) program and includes the assumptions, the boundary conditions, and mesh - generation to investigate the thermal performance of the cylinder embedded in porous media. There are many parameters (air inlet temperature, air outlet 
temperature, the surface temperature of the heater) that have been employed for solving the equations of continuity, momentum, and energy using the software (Ansys Fluent 18).

Porous media are created by insert a momentum source term ${ }^{(11)}$ to the standard fluid flow equations. The source term ( $\mathrm{S}$ ) is formed of two parts; the first term in the right side of equation (1) is a viscous loss term (Darcy term), while the second term in the right side of equation (1) is an inertial loss:

$\mathrm{S}=-\left(\frac{\mu}{\sigma} v i+\mathrm{C}_{2} \frac{1}{2} \rho|v| v i\right)$ where $\alpha$ is permeability

Physical model: The geometry system using for the solution is two dimensions space $(0.4 \times 0.2 \mathrm{~m})$ which in turn represented the boundary of the test section that use in the experimental part, this space contains a circle of $(0.015 \mathrm{~m})$ diameter which is placed in different locations in each test. This space is drawn by applying a software program called solid work 2018 as shown in figure (1).

\section{Assumptions}

The working fluid is air and the flow characteristics are assumed to be as follows: Steady state, Incompressible fluid, two dimensions, Turbulent flow (SST k-omega)

Mesh - generation

In this research, the mesh was generated by using Ansys workbench. A correct computational mesh creation was of eminent significance to simulate the ANSYS (fluent). The results precision was meshing dependent, therefore, it is necessary to reduce the domain mesh size step by step to a suitable level where any increase in the nodes number does not lead to great changes in the results. The mesh for the test section and cylinder is shown in figure (1). For the present case, an average of (31745) nodes are used, after several attempts.

\section{Executions of Boundary Conditions}

Boundary conditions are defined for each zone of the domain as following:

- Inlet condition: The inlet air velocity inter to the duct is $3.68 \mathrm{~m} / \mathrm{s}$ and the inlet air temperature is $24^{\circ} \mathrm{C}$

- Outlet condition: The outlet pressure is assumed to be atmospheric pressure.

- Heat flux from the heater is $241632.57 \mathrm{~W} / \mathrm{m}^{2}$

Cell zone condition: In case of full duct with porous media choose a porous zone and select the porosity (0.463) and type of porous media used is (glass beads)

\section{Governing equations equation:}

The conservation continuity, momentum, and energy equations are written as follows:

Conservation of mass equation:

$$
\frac{\partial u}{\partial x}+\frac{\partial v}{\partial y}+\frac{\partial w}{\partial z}=0
$$

where $\mathrm{u}, v$ and $\mathrm{w}$ are velocity components corresponding to the $\mathrm{x}, \mathrm{y}$ and, $\mathrm{z}$ directions.

* Conservation of momentum equation:

$$
\begin{aligned}
& \frac{1}{g^{2}}\left[u \frac{\partial u}{\partial x}+v \frac{\partial v}{\partial y}+w \frac{\partial w}{\partial z}\right]=-\frac{1}{\rho f} \frac{\partial p}{\partial x}+\frac{1}{z^{2}} v_{e f f}\left(\frac{\partial^{2} u}{\partial x^{2}}+\frac{\partial^{2} u}{\partial y^{2}}+\frac{\partial^{2} u}{\partial z^{2}}\right)-\left[\frac{v f}{k}+\frac{\varepsilon C}{\sqrt{K}}|\vec{V}|\right] u
\end{aligned}
$$

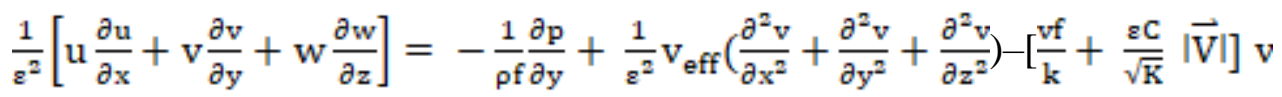

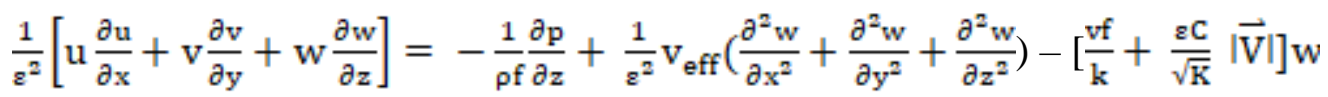


$|\vec{V}|$ Dimensionless absolute velocity

* Conservation of energy equation:

$$
u \frac{\partial T}{\partial x}+v \frac{\partial T}{\partial y}+w \frac{\partial T}{\partial z}=\frac{K_{\theta f f}}{(\rho C p) f}\left(\frac{\partial^{2} T}{\partial x^{2}}\right)+\left(\frac{\partial^{2} T}{\partial y^{2}}\right)+\left(\frac{\partial^{2} T}{\partial z^{2}}\right)
$$

\section{EXPERIMENTAL WORK}

Air enters the tunnel (air duct) by a centrifugal blower; the maximum electrical motor speed is $2900 \mathrm{rev} / \mathrm{minute}$ ( $3 \mathrm{ph}, 2.5 \mathrm{~A}, \mathrm{Y}$ ). To control the amount of air entering the duct, special plates at the inlet of the blower were used. To connect air duct with the blower it is using a diffusive with $\left(0.2 * 0.2 \mathrm{~m}^{2}\right.$ and $0.4 \mathrm{~m}$ length with circular diameter $\left.0.06 \mathrm{~m}\right)$ dimensions. A diffuser followed by air duct (iron plate duct) of $2 \mathrm{~mm}$ thickness, $(0.2 \times 0.2) \mathrm{m}^{2}$ cross-section area, and its length is $3.4 \mathrm{~m}$. this length can be extended to get a uniform flow when it entered the test section and avoid a flow separation phenomena and high turbulence that can obtained by connecting the diffuser and the air duct. Iron plate test section shown in figure (3) Is placed after the air duct of $(0.2 \times 0.2) \mathrm{m}^{2}$ and $0.4 \mathrm{~m}$ length. All the sides of the test section are fixed to the duct except the top side which is movable, utilized to fill and empty the porous element (beads) and change the locations of the heating element. A mesh wire of $1.5 \times 1.5 \mathrm{~mm} 2$ utilized to close the two ends of the test section, prevent the beads from getting out of the test section and fixed the beads in position. There are nine holes of $1 \mathrm{~cm}$ diameter in one sidewall of the test section to fix the heating model element on the test section and connected it to the electrical circuit.

\section{Heating element}

Heating element is consisting of two parts, internal part: cast iron cylinder of $(\mathrm{L}=0.2 \mathrm{~m}$, $D_{\text {out }}=0.01 \mathrm{~m}$ ) made in Germany, heated internally by an electrical heater. The External part: The external diameter of the circular cylinder is $0.015 \mathrm{~m}$ and its length is $0.197 \mathrm{~m}$ made of copper. The temperature distribution is the same in all directions of the heater. To prevent heat transfer to the side walls of the duct, two pieces of a low conductivity rubber putting to insulate two heater ends. To record the surface temperature of the heater (Tw), three groups (twelve thermocouples of $0.9 \mathrm{~mm}$ diameter) installed on the surface of the heater in a very small holes (1 $1 \mathrm{~mm}$ diameter), this thermocouples distributing around the perimeter of the circular heater ( 4 thermocouples separated $90^{\circ} \&$ three thermocouples groups separated by 5 centimeters at one face) See figure (4). Six thermocouples were used to record the temperature of the outlet and inlet of the test section; three is to measure the inlet air temperature and other three thermocouples to measure the outlet temperature.

\section{Instrumentations}

\section{Measurement of air flow and pressure}

Hot-Wire Anemometer type YK-2005AH (1340) was utilized to measure the velocity of inlet air. The average velocity of airflow through the test section measured using the "equal area method" (12). Manometer is used to measure the pressure difference between two ends of test section.

\section{Stabilizer}

Stabilizer type (DACTRON, STAC JAPAN, St, 2000 W, A.C.V. Voltage Regulator) was connected in parallel to the power supply to assure that incoming mains voltage $(220 \mathrm{~V})$ with oscillation of $50 \mathrm{~Hz}$ to produce a voltage of $(220 \mathrm{~V})$ with oscillation of $( \pm 1 \%)$. 


\section{Variac}

Variac type (TDGC) was connected with the stabilizer in parallel to set the input voltage to the cylinder heater as wanted. It receives a voltage range $(110 / 220 \mathrm{~V})$ while supplies a voltage of $(0-250 \mathrm{~V})$.

\section{Voltmeter}

Digital Multimeter type (FUKE, DT 9205) used to measure the voltage that supplied to the heater element. It is able to read a voltage ranged $(200 \mathrm{~V}-750 \mathrm{~V})$, with accuracy of $( \pm 0.05$ V).

\section{Ammeter}

Digital Multimeter type (VCTOR, VC 10C) used to measure an electrical current passing within the heater element. It is able to read a current range (1-100 A) with accuracy of $( \pm 5 \mathrm{x}$ $\left.10^{-4} \mathrm{~A}\right)$.

\section{DATA PROCESSING}

Air mass flow rate is calculated by using the equation:

$$
m=\rho A U
$$

Heat transfer by air can calculate by the relation as follows:

$$
\text { Qair }=m \cdot(\text { Tout }- \text { Tin })
$$

The average surface temperature of the heater element $\mathrm{T}_{\mathrm{w}}$ is calculated by:

$$
\mathrm{Tw}=\frac{\left(T 1+T 2+T 3+T 4+_{\ldots \mathrm{m}}+T 10+T 11+T 12\right)}{12}
$$

And, the mean air temperature $\mathrm{T}_{\text {Mean }}$ calculated from:

$$
\mathrm{T}_{\text {mean }}=\frac{T_{\text {in }}+T_{\text {out }}}{2}
$$

Also, the film temperature over the heater surface calculated by the follows:

$$
\mathrm{T}_{\text {film }}=\frac{T_{\text {mean }}+T_{W}}{2}
$$

The total power supplied to the heater element is calculated from the relationship:

$$
\mathrm{Q} t=\mathrm{I} \times \mathrm{V} \times \cos \theta
$$

where $\Theta$ : phase shift angle (power factor) for three phases.

Note: $\operatorname{Cos}(\theta)=1$ for heater (Manal Hadi 2011), (Hazim Jassim 2012 \}.

Heating losses are calculated by:

$$
Q_{\text {loss }}=Q_{t}-Q_{\text {air }}
$$

And, the net heat transfer is calculated as follows:

$$
\mathrm{q}=\mathrm{Q}_{\mathrm{t}}-\mathrm{Q}_{\text {loss }}
$$

Average heat transfer coefficient (h) calculated according to the relationship by (Qahtan,2005)

$$
\mathrm{h}=\frac{\mathrm{q}}{A s(T w-T \text { mean })}
$$

The effective thermal conductivity $(\mathrm{km})$ is calculated by equation:

$$
k_{m}=\varepsilon k_{f}+(1-\varepsilon) k_{s}
$$

The average Nusselt Number calculated according to the relationship:

$$
N u=\frac{h D_{h}}{k_{\text {aîr }}}
$$

Reynolds Number introduced by the following equation:

$$
R_{e}=\frac{D_{h} U \rho_{\text {air }}}{\mu_{\text {nir }}}
$$

The Surface temperature at each face of the heater is calculated from:

$$
T_{w \theta}=\frac{\Sigma T_{W}}{3}
$$

The local Heat Transfer Coefficient calculated according to the relationship:

$$
h_{\theta}=\frac{q}{A_{g}\left(T_{w \theta}-T_{\text {mean }}\right)}
$$


The local Nusselt Number is calculated by:

$$
N u_{\theta}=\frac{h_{\theta} D_{h}}{k_{m}}
$$

\section{POROUS MEDIA PROPERTIES}

Porosity $(\varepsilon)$ is the volume of the fluid that fills the medium to the total volume of the porous media and can be defining it as the pores between parts of solid material containing the fluid passing through it. The porosity can be expressed mathematically as:-

$\varepsilon=\frac{\forall^{5}}{\forall}$

where: $\forall^{\circ}$ is the difference between total volume $(\forall)$ and the volume of solid material $(\forall s)$.

$\forall^{\circ}=\forall-\forall \mathrm{s}$

First weighting the sample then found its volume $(\forall \mathrm{s})$ by dividing the mass of sample $\left(\mathrm{m}_{\mathrm{s}}\right)$ to the average density $\left(\rho_{\mathrm{s}}\right)$.

$\forall_{s}=\frac{m_{s}}{\rho_{s}}$

The sample of beads was added to the graduated cylinder and the volume $(\forall)$ of the sample was obtained by measuring the graduated cylinder. This checking was repeated several times. The porosity of the glass beads $(5 \mathrm{~mm})$ is found empirically to be $(0.41)$.

\section{RESULTS AND DISCUSSION}

Heat flux: Effect of changing the heat flux $\left[113176.84 \mathrm{~W} / \mathrm{m}^{2}, 169765.27 \mathrm{~W} / \mathrm{m}^{2}, 241632.57\right.$ $\mathrm{W} / \mathrm{m}^{2}$ and, $316895.17 \mathrm{~W} / \mathrm{m}^{2}$ ] on the temperature around the perimeter of heater. for constant Reynolds number the local surface temperature increases as the heat flux increase and, for constant heat flux the distribution of local wall temperature increase and decrease frequently with the angle see figure(5) where at $=90^{\circ}$ and $270^{\circ}$ the thickness of the thermal boundary layer is thin and the surfaces are completely covered with airflow so the temperature will decrease. While at angle $\theta=180^{\circ}$ (stagnation point) the temperature will increase, this is due to the high thermal boundary layer thickness and collection of the hot air at the stagnation point. The maximum value of difference temperature ratio ((Tmax -Tmin)/ Tmax) is 33\%. The effect of changing heat flux on local Nusselt number $(\mathrm{Nu})$ at the perimeter is shown in figure (6), $\mathrm{Nu}$. Number is gradually decreased as the angle increase until $\left(180^{\circ}\right)$ then increases until $\left(270^{\circ}\right)$. This is due to the top and bottom surfaces $\left(\Theta=90^{\circ}, 270^{\circ}\right)$ are completely covered with the airflow. In addition, when the heat flux increase $(\mathrm{h}=\mathrm{Q} / \mathrm{A} . \Delta \mathrm{T}, \mathrm{Nu}=\mathrm{hd} / \mathrm{k})$ the heat transfer coefficient and Nusselt number will increase. In the computational results, the temperature distribution patterns around the perimeter of the cylinder are shown in figure( $7 \mathrm{a})$. the computational results are similar to the experimental results see fig. (7B). the maximum percentage difference between theoretical and experimental results is $1.116 \%$.

Airflow effect: For a particular location (center of the test section p4) \& constant heat flux $\left(241632.57 \mathrm{~W} / \mathrm{m}^{2}\right)$. Figure (8) shows the local surface temperature distribution for the heater perimeter with different $\operatorname{Re}(1560.4,1367.6,1339.3$ and, 1152.87). The temperature gradually increases $\left(0^{\circ}-180^{\circ}\right)$ then gradually decreases $\left(180^{\circ}-270^{\circ}\right)$. The temperature value increases as the Reynolds number decreases because of the less heat transfer lost to the air. It is the same behavior for other locations. Figure (9) shows that the local Nusselt number increases as the Reynolds number increase, this is because of the Reynolds number increases with increases the mass flow rate, so the temperature will decrease and, the local heat transfer coefficient and local Nusselt number will increases. The effect of change the Reynolds 
number on the temperature values [1560.4, 1367.6, 1339.3 and, 1152.87] by Ansys are presented in Table (1). The average surface heater temperature from the Ansys is similar to the experimental results with maximum percentage deviation (1.62\%) at $\operatorname{Re}(1560.4)$, also the velocity distribution around the heater explain in figure (10).

\section{Heater position:}

Figure(11) shows the effect of changing heater positions within the test section by $5 \mathrm{~cm}$ distance between one location and another see figure(3). It is noted that when changing the cylinder locations, the behavior of the temperature distribution are similar and the values for any location are close, the maximum difference in temperature between location 1 and 7 in $\mathrm{x}$ direction is $(1.431 \%)$, between locations 1 and 3 in y-direction is equal $(0.678 \%)$ this is because airflow that entered the test section is fully developed and, the same section area of the test section and heat lost by forced convection. Computational results show that the temperature distribution patterns and values around the perimeter of the cylinder when changing the location is similar for all positions see figure(7) and table (2).

\section{Average Nusselt number with Reynolds number}

Figure (12) shows that average Nusselt number increases as the Reynolds number and heat flux increase. Increase the Reynolds number leads to an increase in the mass flow rate so this cause high heat transfer between air and heater (i.e. high average $\mathrm{Nu}$ ). The correlation between $\mathrm{Nu} \& \operatorname{Re}$ is $N u=0.0514 \operatorname{Re}^{0.5012}\left(\frac{x}{X}\right)^{-0.54}$. The average deviation between experimental \& correlation results is $0.21 \%$. Table (3) explains the experimental effectiveness of using porous media on improving convection heat transfer of the heater element in the cross airflow. Heat transfer coefficient of the heating element inside porous medium is larger more than from that in clear duct at the same rate of the airflow (mass flow). The enhancement in heat transfer for the heater embedded in porous medium is $67.4 \%$ [E\% = $\left.\left(h_{\text {porous }}-h_{\text {empty }}\right) / h_{\text {porous }}\right]$. Figure (13) shows the two computational cases of temperature distribution, with and without porous media where the maximum temperature in case of absence the porous media is $91.04{ }^{\circ} \mathrm{C}$ while in case of presence porous media is $47.85{ }^{\circ} \mathrm{C}$ at the same heat flux $241632.57 \mathrm{~W} / \mathrm{m}^{2}$.

\section{Validation of the present work}

Figure(12) shows that the average Nusselt number has similar behavior to those presented in ref. [Ahmed H. Ahmed 2010]. The average Nusselt number was increased as the Reynolds number increase. Also, the Nusselt number increase with increase the heat flux and, this is achieved in both studies. Table 4 shows the correlations of Nusselt number with Reynolds number at a different heat flux. At $316895.1 \mathrm{w} / \mathrm{m}^{2}$ heat flux the correlation between $\mathrm{Nu} \& \mathrm{Re}$ numbers is $\mathrm{Nu}=6.0015 \ln (\mathrm{Re})-35.798$

\section{CONCLUSIONS}

The present research focuses on the effect of using the porous media on forced convection heat transfer from a cylinder placed in different location within the test. The conclusions based on the experimental and theoretical results from are follows. Accordingly, the following conclusions are:

1. The maximum temperature is at the stagnation point (i.e. $\Theta=180^{\circ}$ ) and, the minimum temperature is at $\left(\Theta=90^{\circ}, 270^{\circ}\right)$.

2. The local Nusselt number $\left(\mathrm{Nu}_{\Theta}\right)$ decreases as the angle increases until $\Theta=180^{\circ}$ then increases towards $\Theta=270^{\circ}$.

3. The Nusselt number at a constant heat flux and beads diameter $(5 \mathrm{~mm})$ is directly proportional to Reynolds number such that $N u=0.0514 R e^{0.5012}\left(\frac{x}{X}\right)^{-0.54}$. The average 
deviation between experimental \& correlation results is $0.21 \%$. It also increases with the increase in heat flux at a constant Reynolds number.

4. The surface temperature distribution of the cylinder has the same trend for the different location within the test section with a small variation value not exceeds $(1.431 \%)$.

5 . The use of porous material significantly improves heat transfer by $(67.4 \%)$.

6. The maximum percentage deviation between the experimental and theoretical results is $1.622 \%$.

7. The comparison between the present and previous work gives good agreements.

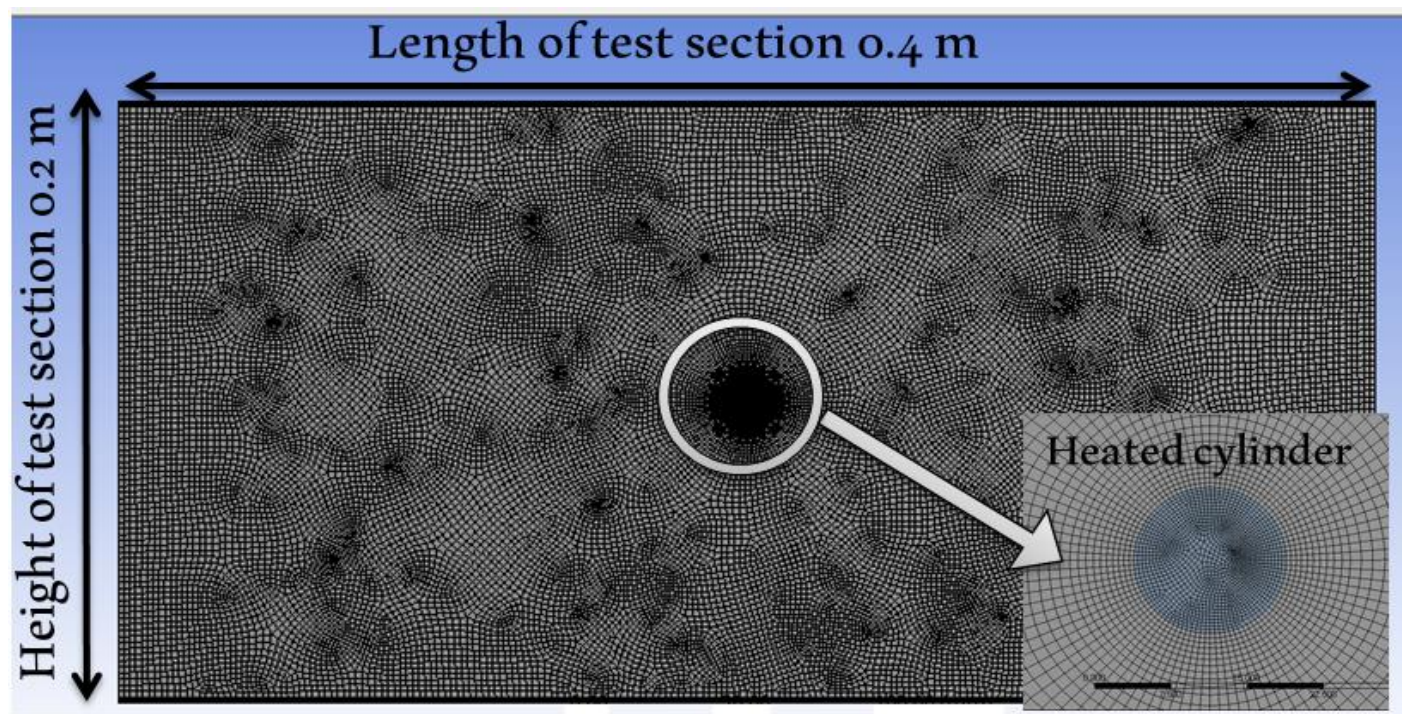

Fig. (1): Physical model and mesh generations

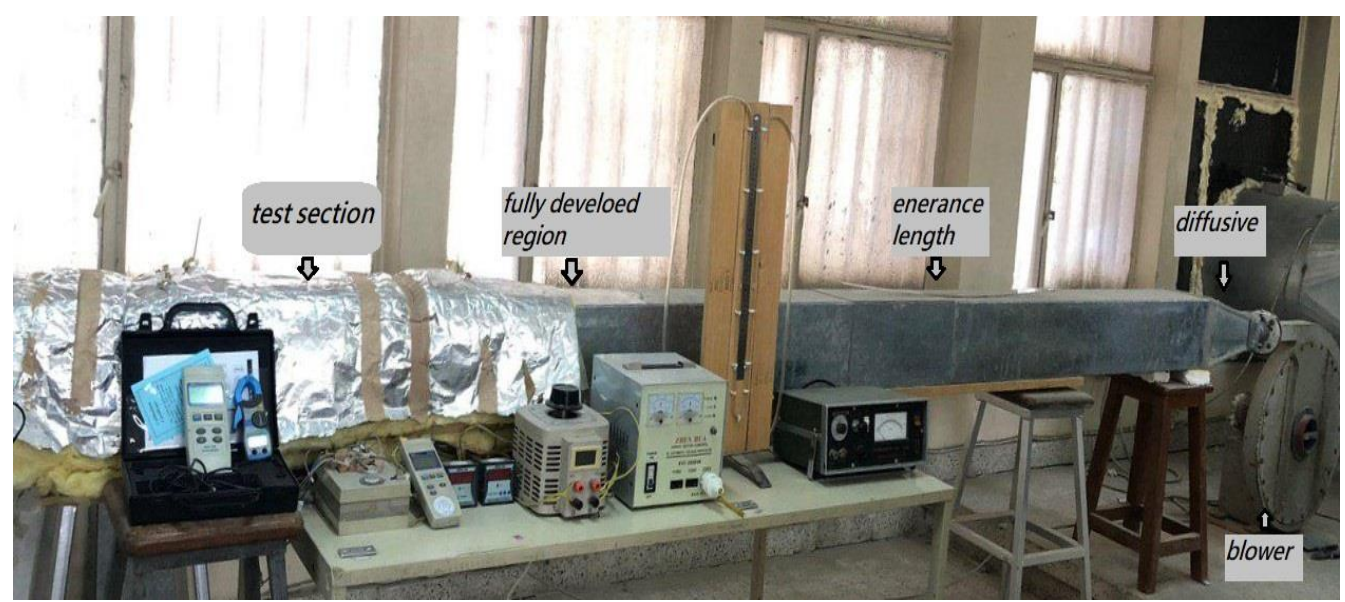




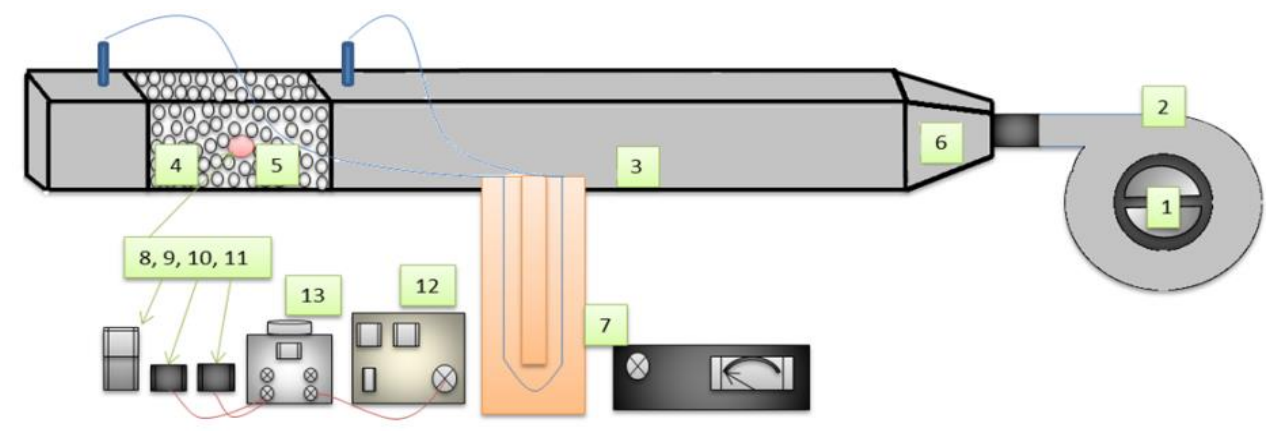

\begin{tabular}{|c|c|c|c|c|c|c|c|}
\hline 1 & gate & 5 & Heater model & 9 & Hot-wire & 13 & variac \\
\hline 2 & blower & 6 & Diffuser & 10 & Voltmeter & - & - \\
\hline 3 & Duct & 7 & Manometer & 11 & Ammeter & - & - \\
\hline 4 & Test section & 8 & Thermocouples & 12 & Stabilizer & - & - \\
\hline
\end{tabular}

Fig. (2) Schematic \& photographically of air duct and test section
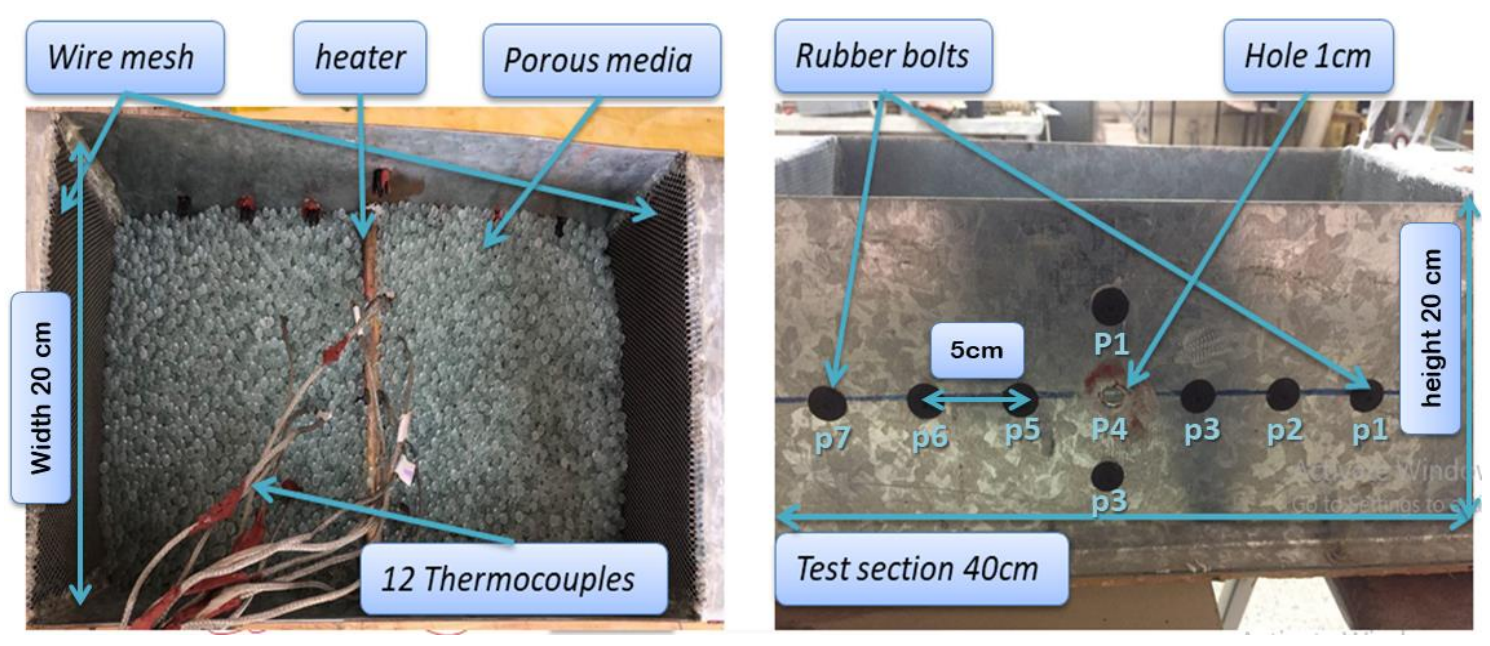

Fig. (3) Test section and positions of the heater

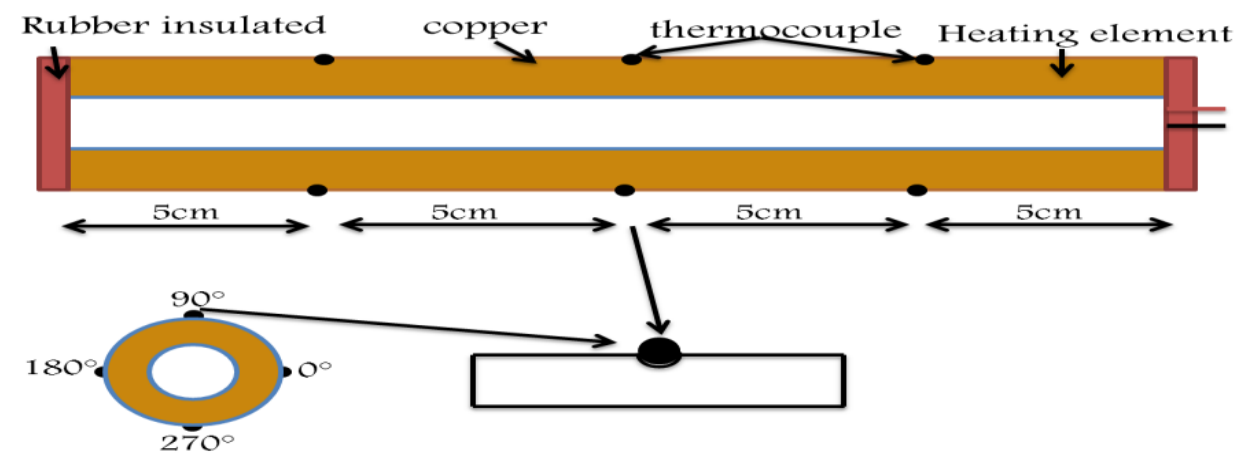




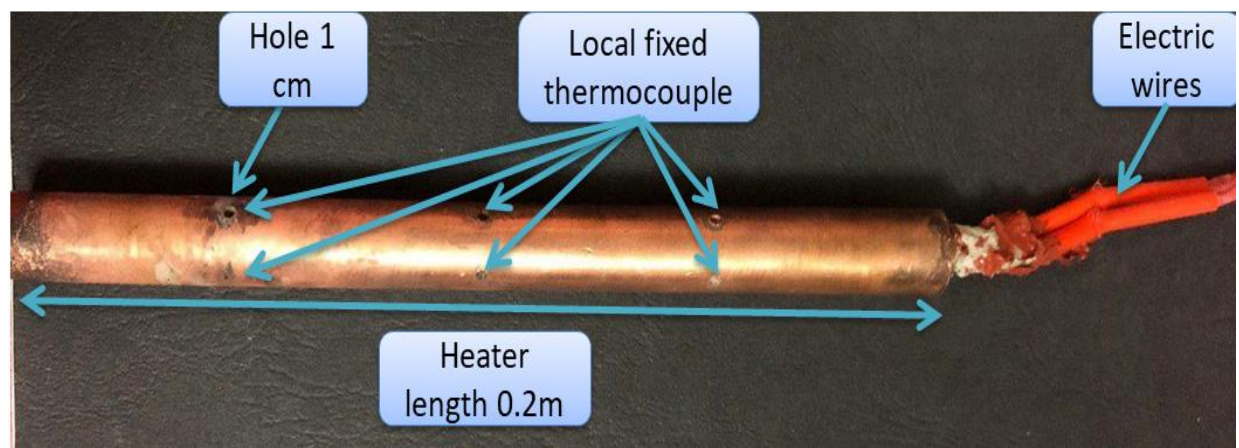

Fig. (4) the thermocouples distribution around circular cylinder.

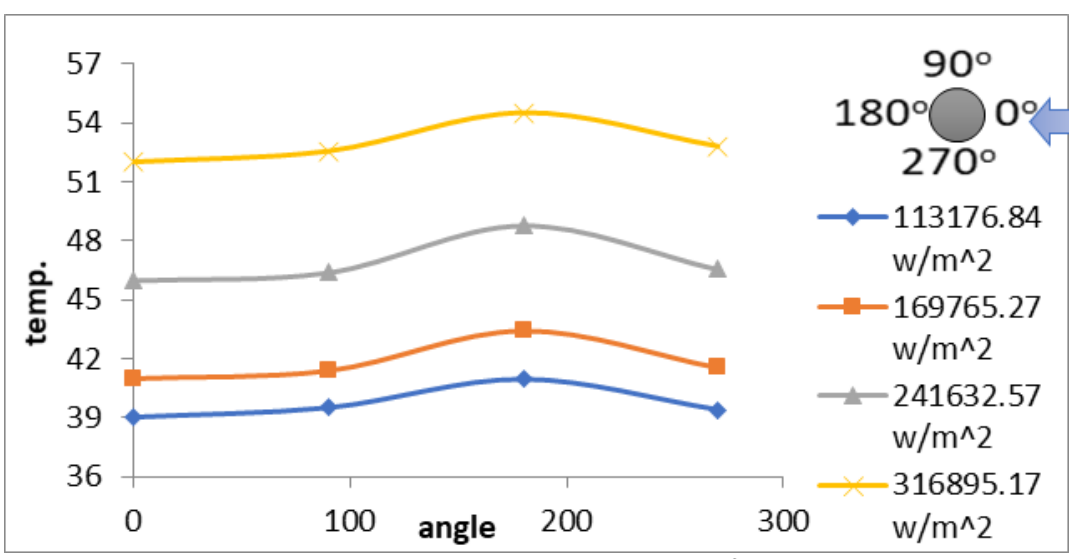

Fig. (5) surface Temperature of the heater $\left({ }^{0} \mathrm{C}\right)$ with Angle at different heat flux, $\operatorname{Re}=1560.4$ (position 4)

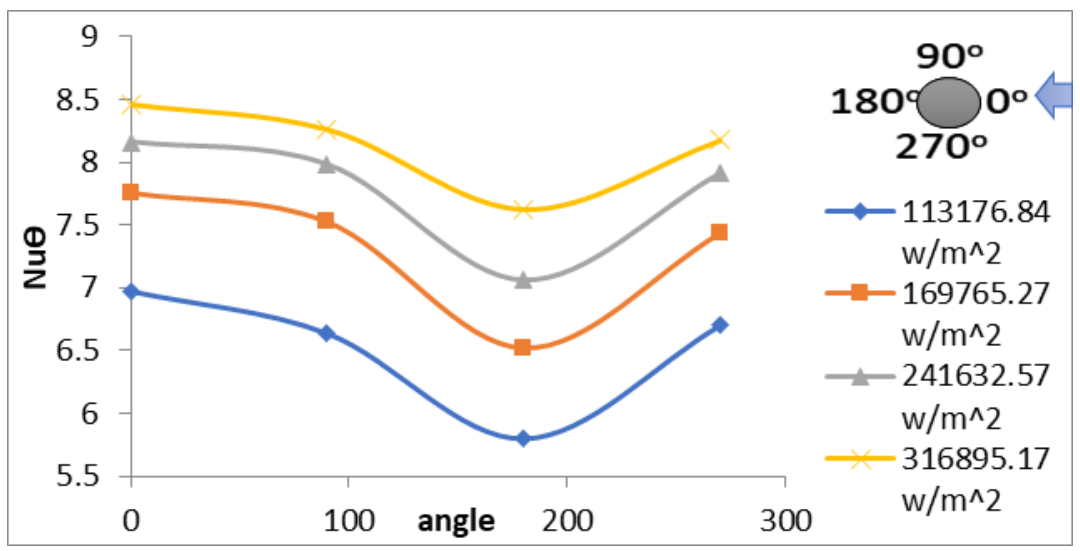

Fig. (6) Local $\mathrm{Nu} \Theta$ with Angle at different heat flux at constant $\mathrm{Re}=1560.4$, position (4) 


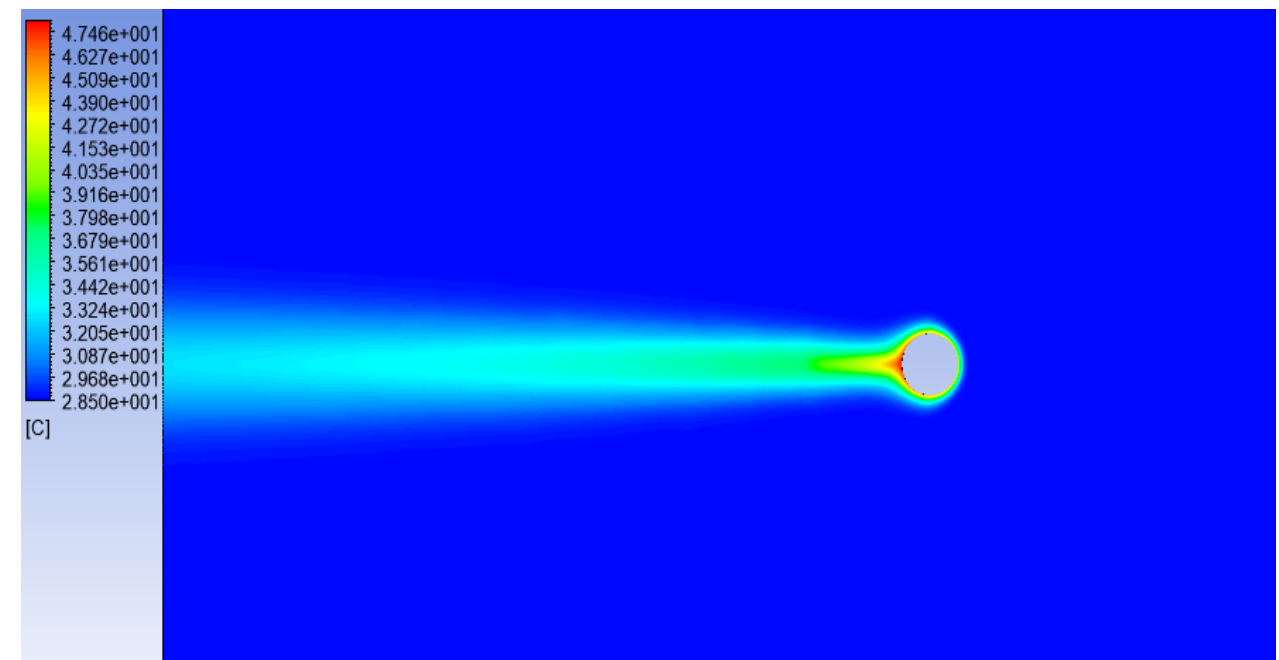

Fig.(7.a)temperature distribution around the cylinder perimeter at $241632.57 \mathrm{~W} / \mathrm{m}^{2}, \mathrm{Re}=$ 1533.3 using ANSYS program

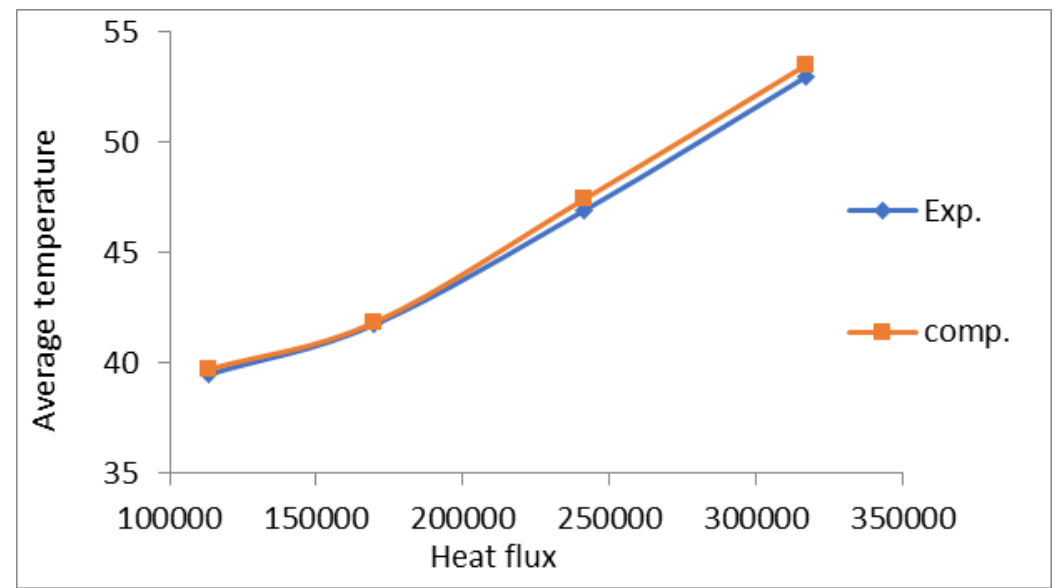

Fig.(7.b)comparison between the experimental and computational values of the surface temperature of the cylinder with heat flux changing

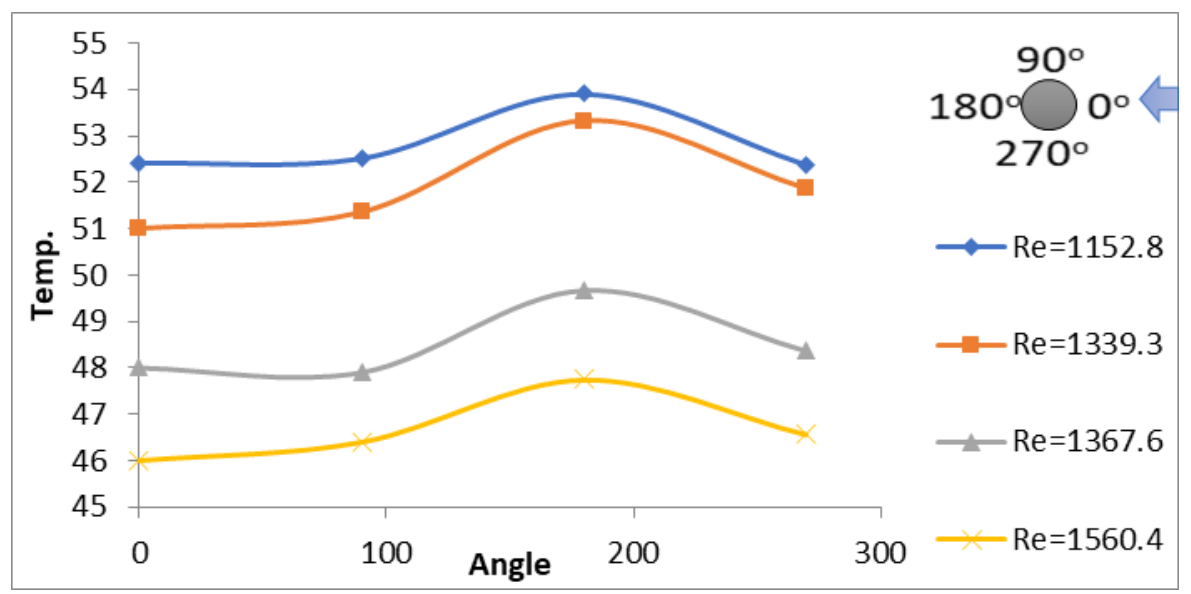

Fig. (8) surface Temperature $\left({ }^{0} \mathrm{C}\right)$ Profile with angle for different $\operatorname{Re}$ (1560.4to 1152.8), at $241632.57\left(\mathrm{~W} / \mathrm{m}^{2}\right)$, Position 4 


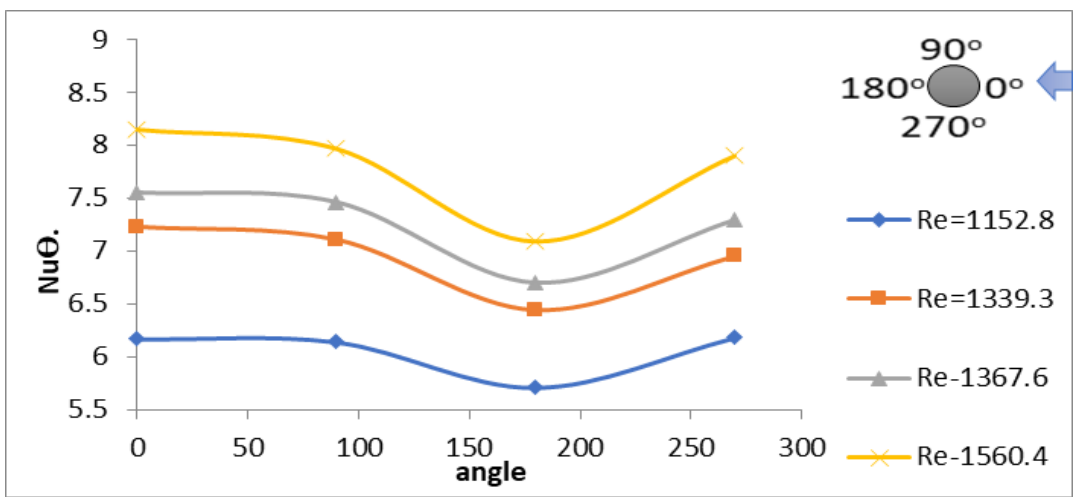

Fig. (9) local Nusselt number with angle for different Re (1560.4to 1152.8), at 241632.57 $\left(\mathrm{W} / \mathrm{m}^{2}\right)$, Position 4

Table (1) effect of changing $\mathrm{Re}$ on surface heater temperature and compare it with experimental work

\begin{tabular}{|c|c|c|c|c|}
\hline$R e$ & 1152.8 & 1339.3 & 1367.6 & 1560.4 \\
\hline theo. $T_{\text {avg }}$ & $53.03^{\circ} \mathrm{C}$ & $51.93^{\circ} \mathrm{C}$ & $48.85^{\circ} \mathrm{C}$ & $47.46^{\circ} \mathrm{C}$ \\
\hline $\exp . T_{\text {avg }}$ & $52.79^{\circ} \mathrm{C}$ & $51.88^{\circ} \mathrm{C}$ & $48.48^{\circ} \mathrm{C}$ & $46.69^{\circ} \mathrm{C}$ \\
\hline$\frac{T_{\text {theo }}-T_{\exp }}{T_{\text {theo }}}$ & $0.452 \%$ & $0.0962 \%$ & $0.757 \%$ & $1.622 \%$ \\
\hline
\end{tabular}

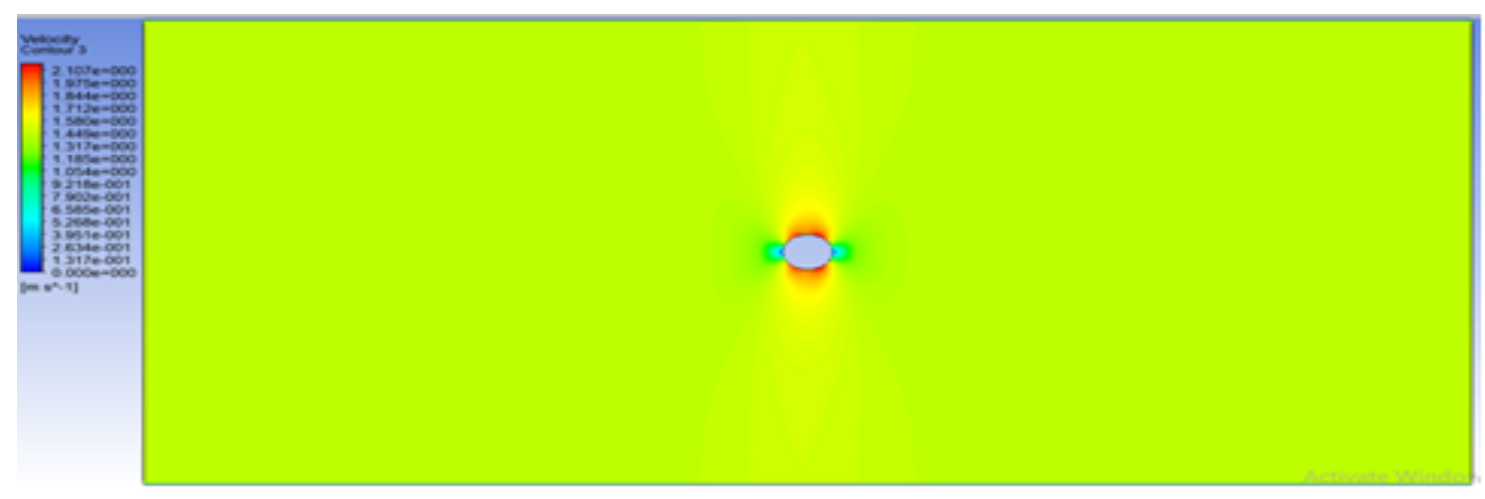

Fig. (10) velocity distribution around the cylinder at $241632.57 \mathrm{~W} / \mathrm{m}^{2}$ heat flux, position4, $\operatorname{Re}=1531$
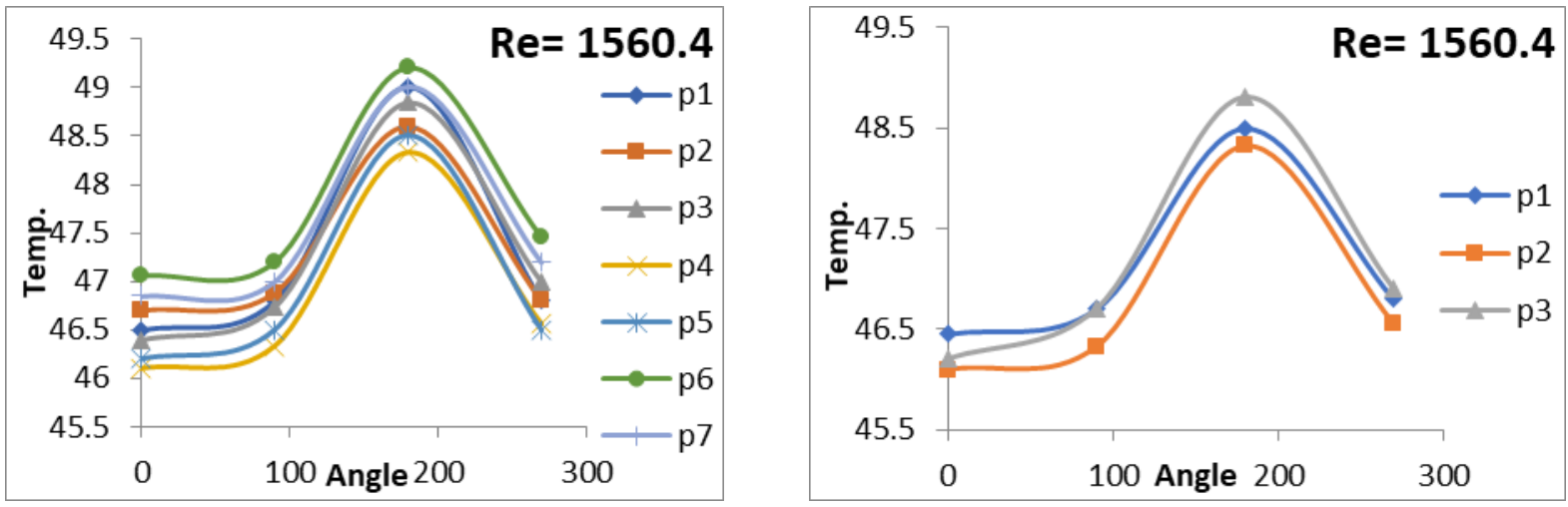

Fig. (11) surface temperature Profile with Angle for different heater position at constant $\mathrm{Re}$ and $\left(241632.57 \mathrm{~W} / \mathrm{m}^{2}\right)$, for positions (1-7) in $\mathrm{x}$-axis, and positions (1-3) in $\mathrm{y}$ - axis 
Table 2 effect of change heater position on average surface temperature of the heater

\begin{tabular}{|l|l|l|l|l|l|}
\hline location & $p_{1}$ in $x$-axis & $p_{4,2}$ & $p_{7}$ & $p_{1}$ in y-axis & $p_{3}$ \\
\hline theo. $T_{\text {avg }}$ & $47.25^{\circ} \mathrm{C}$ & $47.46^{\circ} \mathrm{C}$ & $47.30^{\circ} \mathrm{C}$ & $47.23{ }^{\circ} \mathrm{C}$ & $47.25{ }^{\circ} \mathrm{C}$ \\
\hline exp. $T_{\text {avg }}$ & $47.27^{\circ} \mathrm{C}$ & $46.83{ }^{\circ} \mathrm{C}$ & $47.51{ }^{\circ} \mathrm{C}$ & $47.11^{\circ} \mathrm{C}$ & $47.15^{\circ} \mathrm{C}$ \\
\hline$\frac{T_{\max }-T_{\min }}{T_{\max }}$ & $0.042 \%$ & $1.32 \%$ & $0.44 \%$ & $0.25 \%$ & $0.211 \%$ \\
\hline
\end{tabular}

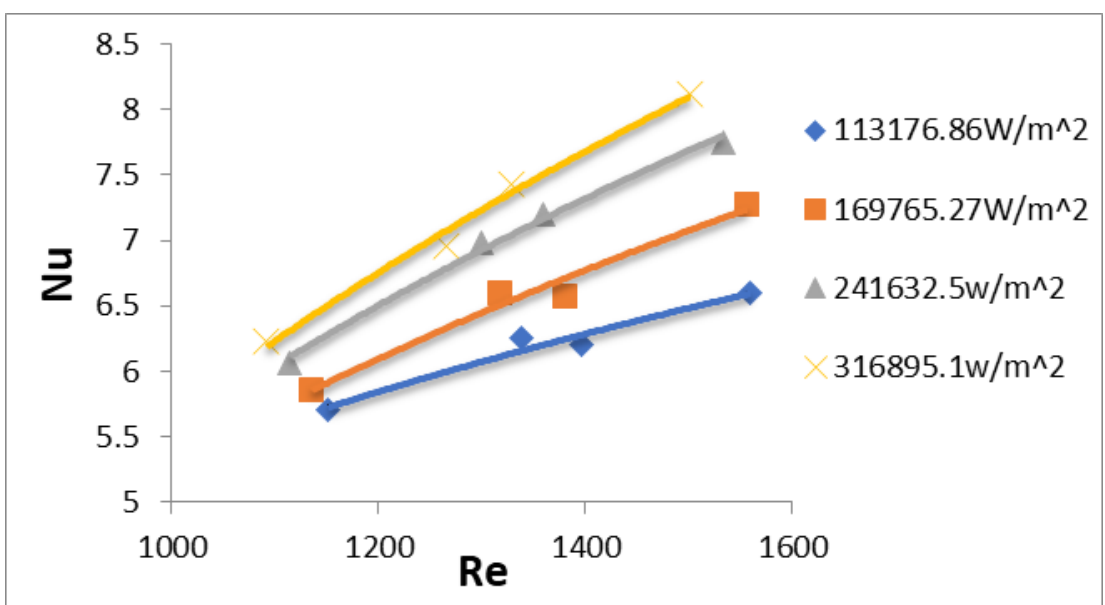

Fig. (12) increase of average Nusselt numbers with Reynolds number

Table (3) Heat transfer enhance for position 4, 169765.2 W/m² heat flux (experimental results)

\begin{tabular}{|l|l|l|l|l|}
\hline test section & $\mathrm{m} \cdot(\mathrm{kg} / \mathrm{s})$ & $\mathrm{Tw}\left({ }^{\circ} \mathrm{C}\right)$ & $\mathrm{h}\left(\mathrm{w} / \mathrm{m}^{2} . \mathrm{c}\right)$ & percentage \\
\hline porous & 0.1049 & 42.2313 & 200.52 & \multirow{2}{*}{$67.4 \%$} \\
\hline empty & 0.1093 & 63.7875 & 65.18 & \\
\hline
\end{tabular}
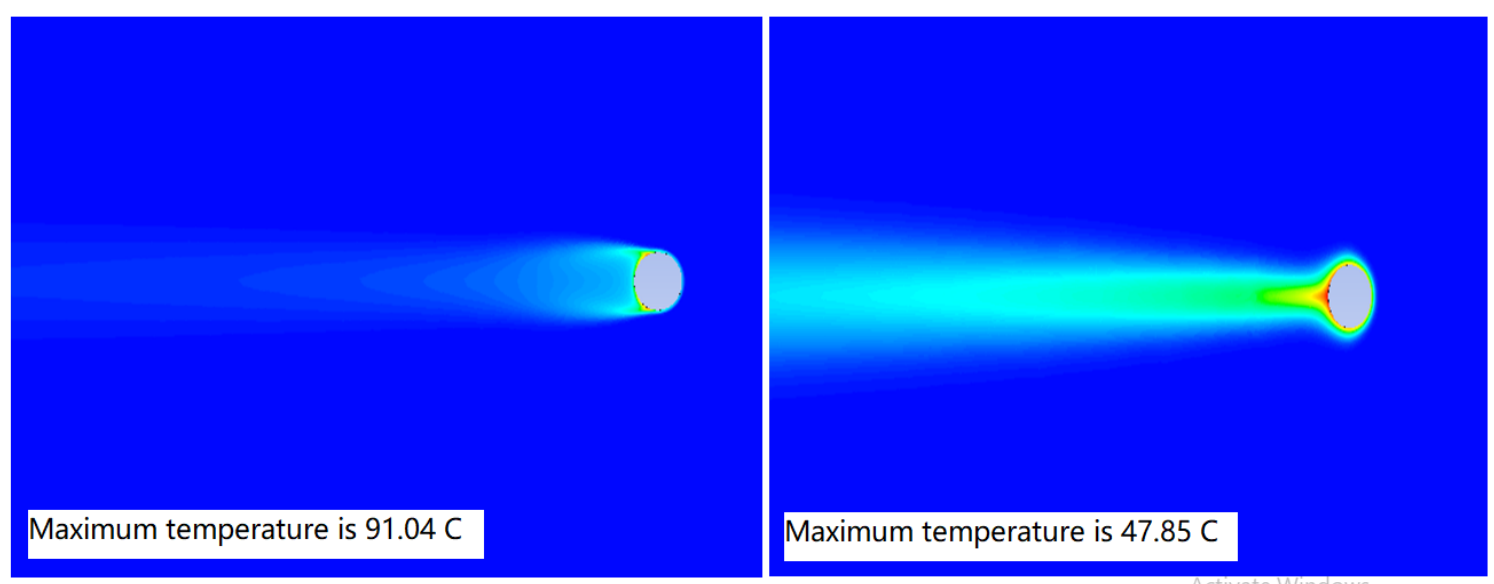

Fig. (13) enhancement of heat transfer where the $T_{\max }$ in case A: without porous media is $91.04{ }^{\circ} \mathrm{C}$ B: with porous media is $47.85{ }^{\circ} \mathrm{C}$ (position 4 , ds $=5 \mathrm{~mm}, 241632.57 \mathrm{~W} / \mathrm{m}^{2}$ heat flux) 


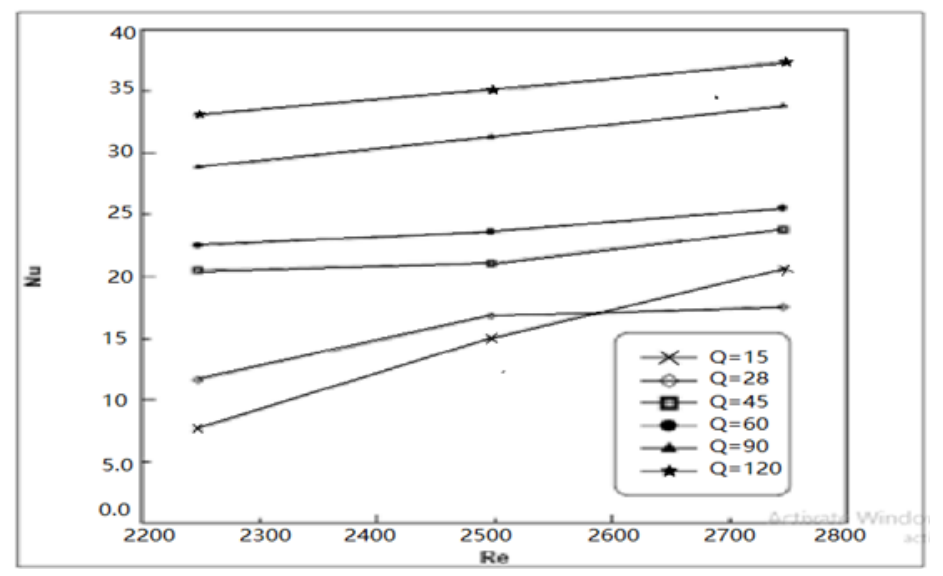

Figure 14 average Nusselt numbers with Reynolds number

Table (4) correlations of $\mathrm{Nu}$ with $\mathrm{Re}$ at different heat flux

\begin{tabular}{|l|c|c|c|c|}
\hline \multicolumn{1}{|c|}{ Ref. } & $\mathrm{Nu}$ & $\mathrm{Re}$ & $a$ & $b$ \\
\hline $\begin{array}{c}\text { present work } \\
12 \mathrm{~mm}\end{array}$ & $\mathrm{Nu}=$ alnRe- $b$ & $1500<\operatorname{Re}<2200$ & $2.8<a<6$ & $14.4<b<35.79$ \\
\hline Ref.11 & $\mathrm{Nu}=$ alnRe- $b$ & $2000<\operatorname{Re}<3000$ & $10<a<27.6$ & $66.3<b<183$ \\
\hline
\end{tabular}

\section{REFERENCES}

Ahmed al- sammarraie,"An Experimental Study on Forced Convection Heat Transfer from an Embedded Horizontal Cylinders Array in A Porous Medium in Cross Flow" Tikrit Journal of Engineering Sciences, V. 14, No. 1, march 2007.

Bejan, A. 2003. "Convection Heat Transfer", Chap. 10, John Wiley and sons Ins., 1984

Al - Omar" Numerical Study of Inertia Effect on Natural Convection in A Horizontal Porous Cavity", M.Sc., Mosul Univ.

K. Nasr, S. Ramadhyani, R. Viskanta" An Experimental Investigation on Forced Convection Heat Transfer From a Cylinder Embedded in a Packed Bed", Journal of Heat Transfer, V. 116, pp73-80, 1994

M. Layeghi, A. Nouri-Borujerdi," Darcy Model for the Study of the Fluid Flow and Heat Transfer Around a Cylinder Embedded in Porous Media", International Journal for Computational Methods in Engineering Science and Mechanics, V. 7, P.P 323329,2006

Gazy F. Al-Sumaily, John Sheridan, Mark C. Thompson," Analysis of forced convection heat transfer from a circular cylinder embedded in a porous medium", International Journal of Thermal Sciences V. 51, pp. 121-131, 2012

Muhammed Asmail Eleiwi,"Theoretical and Experimental study of forced convection heat transfer from a horizontal cylinder embedded in porous medium" Journal of 
Kirkuk University - Scientific Studies ,V.7, No.2, 2012

Gazy F. Al-Sumaily," Forced Convection Heat Transfer From a Bank of Circular Cylinders Embedded in a Porous Medium", Journal of Heat Transfer, V. 136 / PP.1-11

Mirlatifia.m., ghazalm, "Forced convection heat transfer from a circular cylinder embedded in porous Media” ,Mechanical Engineering Department ,EMU ,Via Mersin 10, Turkey, 2010.

Jasim M. Abood, "Force Convection Heat transfer from a Different Cross Section Cylinder Embedded in Porous Media" Al-Nahrain Journal for Engineering Sciences (NJES), V.20, No.3, pp.727-736, 2017

Ahmed H. Ahmed ," Forced Convection about a Horizontal Cylinder Embedded in a Porous Medium" Foundation of Technical Education- Technical Institute Hawija Journal of Kirkuk University - Scientific Studies, V.5, No.2, 2010.

Eric M. Banks Christopher, "Airflow Traverse Comparisons using The Equal-Area Method ,Log-Tchebycheff Method and the Log-Linear Method" NUCON International ,Inc. Columbus, Ohio.

Manal Hadi Saleh," Parametric study of laminar free convection in inclined porous annulus with fins on the inner cylinder", Ph.D, University of Baghdad, 2011

Hazim Jassim Jaber, "Heat Transfer in a partially Opened Cavity Filled With a Porous Media", M.Sc. University of Technology, 2012

Qahtan," Forced Convection Heat Transfer Through and over porous layer on a heated wall at constant temperature" M.Sc. University of Technology, Mechanical engineering department, 2005 